\title{
Desain Game Simulasi Pembuatan Makanan Khas Daerah Sumatera Menggunakan Pendekatan Framework Design Play Experience
}

\author{
FERRY KURNIAWAN ${ }^{1}$, AGUS KOMARUDIN ${ }^{2}$, REZKI YUNIARTI ${ }^{3}$ \\ 1,2,3 Jurusan Teknik Informatika, Fakultas Sains dan Informatika \\ Universitas Jenderal Achmad Yani \\ Jl. Terusan Sudirman, Cimahi \\ Email : sony.acro.s90@gmail.com
}

\begin{abstract}
ABSTRAK
Makanan khas daerah di Indonesia memiliki cita rasa yang khas akan rempahrempah dan keunikan setiap jenis makanannya serta diminati masyarakat Indonesia. Seiring perkembangan zaman, beragam jenis makanan masa kini menjadi pilihan utama masyarakat pada zaman sekarang karena kurangnya promosi dan tampilan yang kalah menarik. Berdasarkan permasalahan di atas, kemudian dirancang sebuah media pembelajaran sekaligus promosi yang bertujuan untuk menarik perhatian masyarakat agar dapat tertarik kembali dengan makanan khas daerah. Media pembelajaran yang dimaksud adalah game. Game akan menyampaikan materi pembelajaran mengenai tata cara pembuatan makanan khas daerah tersebut dan mengenal bahan-bahan dasar yang diperlukan sesuai berada di dunia nyata. Penelitian ini bertujuan untuk membangun sebuah game simulasi tentang tata cara membuat makanan khas daerah tersebut dan memilih bahan yang sesuai dengan resep yang bertujuan untuk mengenalkan kepada masyarakat umum dan memperkenalkan kembali makanan khas daerah Indonesia bahwa makanan tersebut tidak kalah lezat dan menarik dengan makanan masa kini. Perancangan game akan menggunakan sebuah pendekatan Framework DPE (Design-Play-Experience).
\end{abstract}

Kata kunci: pembuatan makanan, makanan khas daerah, media pembelajaran, simulasi, framework dpe.

\begin{abstract}
Indonesian local food has a distinctive flavor of spices and uniqueness of every kind of food and the interest of Indonesian people. As time goes by, various types of food nowadays become the main choice of the Indonesian people because lack of promotion and a less attractive appearance. Based on the problem, then designed a learning media and promotion that aims to attract the attention of people to be re-interested with local food. The intended learning media is a game. The Game will convey learning materials about the procedure of making local food and get to know the basic ingredients needed to be in the real world. This research
\end{abstract}


aims to build a simulation game on the ordinance of making food typical of the area and choosing the ingredients that suit the recipe that aims to introduce to the general public and reintroduce the typical food Indonesian area that the food is not less delicious and interesting with the present food. Game design will use a Design-Play-Experience (DPE) approach.

Keywords: food making, traditional foods, learning media, simulation, dpe framework. 


\section{PENDAhUlUAN}

Makanan tradisional sebagai makanan khas daerah merupakan salah satu unsur kebudayaan yang tersebar di berbagai daerah di Indonesia. Masing-masing daerah memiliki jenis makanan yang disertai variasi dan cara penyajiannya. Makanan sangat erat kaitannya dengan bahan pembuatannya, karena itu bahan-bahan mentah untuk makanan suatu masyarakat atau suku bangsa dipengaruhi oleh potensi alam dimana mereka bermukim [1].

Banyaknya makanan khas daerah di Indonesia benar-benar membuat suatu keragaman dan keunikan tersendiri. Jenis-jenisnya pun beragam, mulai dari makanan pokok, lauk dan cemilan. Khusus untuk makanan khas daerah Sumatera, makanan ini memiliki karakteristik yang unik dan cita rasa yang khas terutama pada bagian bahan pokok yang digunakan untuk membuat makanan tersebut. Seiring berkembangnya zaman, tidak sedikit makanan tradisional Indonesia yang mulai tidak diminati karena terkenalnya makanan dari negeri asing yang masuk ke negeri Indonesia. Tidak dipungkiri generasi muda sekarang lebih menyukai makanan cepat saji dari negara asing daripada makanan tradisional asli Indonesia. Dari pernyataan tersebut maka dapat disimpulkan bahwa masyarakat zaman dahulu menyukai makanan lokal dan karena tergesernya zaman, sehingga di zaman sekarang masyarakat lebih menyukai makanan luar negeri daripada makanan lokal, maka harus ada tindakan untuk mengenalkan pada masyarakat tentang makanan tradisional Indonesia [2].

Perkembangan teknologi khususnya dalam dunia game pun terbilang pesat, hal tersebut dapat dimanfaatkan untuk melakukan simulasi yang berkaitan dengan bidang kuliner ke dalam bentuk game agar menarik perhatian masyarakat mengenai makanan-makanan tersebut. Begitu pula game di zaman sekarang tidak memandang usia dari mulai anak kecil, remaja hingga dewasa. Game tidak hanya bermanfaat agar memperoleh kesenangan, kepuasan, ataupun merubah suasana hati, tetapi game juga bermanfaat sebagai media edukatif dan bertujuan untuk memberi pengalaman atau experience bagi yang memainkan game tersebut [3]. Berdasarkan hal tersebut tujuan awal pembangunan game sebagai media promosi agar produk dapat dikenalkan kepada masyarakat umum dan juga dapat meningkatkan hasil pendapatan [4]. Game juga dapat menjadi suatu hal yang dapat melatih saraf otak manusia dan sangat penting bagi perkembangan otak manusia. Seorang manusia akan mulai berfikir jika sudah dihadapkan dengan sebuah masalah, sedangkan pada sebuah game seseorang dapat dihadapkan dengan berbagai macam masalah dan dituntut untuk memecahkannya.

Game dalam penelitian ini dinamakan Cooking Brave yang dikemas menjadi aplikasi android mobile game dengan menggunakan pendekatan formal framework DPE (Design-PlayExperience) agar game yang dibangun memenuhi semua elemen-elemen yang dibutuhkan dalam game design dan membentuk struktur game yang baik agar makna yang dimaksud tersampaikan.

\section{STUDI PUSTAKA}

Penggunaan media game sebagai media pembelajaran saat ini sudah banyak. Game dibangun untuk digunakan sebagai media pembelajaran dalam bentuk game simulasi untuk mengajarkan kepada kalangan anak-anak hingga dewas bagaimana cara memasak yang benar serta mengenalkan nama bahan-bahan serta nama makanan yang akan dibuat [5]. Game simulasi hadir sebagai media latihan melakukan pekerjaan sehari-hari [6]. Dalam proses gamification, hal tersebut dapat direpresentasikan ke dalam bentuk game [7]. Pelestarian budaya pun dapat dilakukan melalui media game dalam bentuk mobile gadget [8]. Pengenalan makanan khas Indonesia juga dilakukan melalui media game edukasi yang menghasilkan media pembelajaran yang bersifat interaktif [9]. Game mengajak pemain untuk mencoba 
membuat salah satu makanan asli Indonesia dengan mengikuti resep yang ada tanpa tahu apa nama makanan yang dibuat karena nama makanan akan dijadikan sebagai kuis yang harus dijawab oleh pemain di akhir game. Game simulasi sering kali menggambarkan dunia di dalamnya sedekat mungkin dengan dunia nyata dan memperhatikan detil berbagai faktor. Video game jenis ini membuat pemain harus berfikir untuk mendirikan, membangun dan mengatasi masalah dengan segala persoalan yang ada [10]. Melalui media game, masyarakat memungkinkan untuk memperoleh pengalaman dan hal baru tanpa adanya rasa terbebani karena media ini bersifat interaktif dan sangat menarik untuk dimainkan karena pengaruh dari cerita dan gambar yang disajikan di dalam game.

Kerangka kerja framework DPE menyediakan satu pendekatan formal dalam perancangan game dengan pemain serta dapat membantu pembuat game untuk melihat persepsi game agar lebih baik. Pengenalan sebuah Kota di Indonesia melalui media game sudah dilakukan dan memberikan sebuah informasi pengetahuan baru kepada pemain karena adanya peran dari framework DPE. Hal ini ditunjukan dengan adanya komponen dynamics dalam layer play dari pemain yang didominasi oleh discovery dan mastery [11]. Salah satu game yang menerapkan framework DPE adalah game pengidap kebutaan nada. Bagaimana fungsi dari game ini ialah untuk mengukur kebutaan nada tinggi atau rendah pada pemain. Alasan game ini tidak menggunakan framework MDA adalah tidak tepatnya hasil evaluasi experience yang didapatkan dari pemain, diperlukannya pengujian berkala mengenai experience dan game ini ber-genre serious game. Berdasarkan hasil evaluasi pemain yang di dapatkan dari Playtesting, game yang dibangun mendapat nilai terendah yang tidak terdiagnosis kebutaan nada sebesar $33 \%$ dan nilai terbesar yang terdiagnosis kebutaan nada sebesar $86 \%$ dari total 3 responden selama tujuh hari berturut-turut pengujian [12]. Namun, jika pemain merasa experience yang terdapat dalam game masih kurang maka pemain tersebut dapat melakukan feedback ke pembuat game agar game yang dibuat lebih baik dari sebelumnya. Itulah kinerja dari framework DPE [13].

\section{GAME SIMULASI DAN DPE FRAMEWORK}

\subsection{Game Simulasi}

Game adalah permainan terdiri atas sekumpulan peraturan yang membangun situasi bersaing dari dua sampai beberapa orang atau kelompok dengan memilih strategi yang dibangun untuk memaksimalkan kemenangan sendiri ataupun untuk meminimalkan kemenangan lawan [14]. Game atau permainan adalah sesuatu yang dapat dimainkan dengan aturan tertentu sehingga ada yang menang dan ada yang kalah, biasanya dalam konteks tidak serius dengan tujuan refreshing [15]. Game bertujuan untuk menghibur, biasanya game banyak disukai oleh kalangan anak-anak hingga orang dewasa. Game penting dalam perkembangan otak, untuk meningkatkan fokus dan melatih keterampilan seseorang dalam memecahkan suatu masalah yang terdapat dalam video game.

Game jenis ini sering kali menggambarkan dunia di dalamnya sedekat mungkin dengan keadaan di dunia nyata dan memperhatikan dengan rinci berbagai faktor seperti melakukan suatu kegiatan, membangun sebuah gedung atau rumah, memecahkan masalah, mengatur kehidupan dan sebagainya.

\subsection{DPE Framework}

Design Play Experience (DPE) framework diciptakan sebagai perluasan dari MDA framework yang ditujukan untuk kebutuhan perancangan serious game untuk pembelajaran experience pemain, yang sementara mencoba ditujukan untuk beberapa dari penghalang semantic [12]. Sebagaimana MDA, DPE juga menggambarkan hubungan antara perancang dengan pemain. Melalui tahapan awal, seorang perancang membuat desain permainan, kemudian pemain 
mulai memainkan permainan, hingga akhirnya pemain mendapat pengalaman dari permainan tersebut. Karena perancang hanya dapat mengontrol secara langsung pada tahap perancangan, maka untuk mengoptimalkan perancangan, harus didasarkan pada aspek-aspek pencapaian yang dituju. Framework DPE bertujukan bahwa desain tidak hanya terdiri dari mekanisme permainan, tetapi juga mencakup konten pedagogis yang harus dipelajari yaitu karakter, latar, dan narasi cerita yang akan diceritakan dan antarmuka pengguna. Sesuai layer yang terdapat dalam framework DPE juga menggabungkan dengan layer teknologi yang mendasari sebagai prasyarat mendasar untuk membangun game, dan untuk menengahi antara aspek Design-Play-Experience dari sebuah game. Winn mengatakan bahwa Aesthetics (yang berada dalam framework MDA) dengan Experience, mengakui bahwa Aesthetics dari sebuah game tidak diterima secara langsung oleh pemain, tetapi dialami secara individual, subyektif dan unik [18].

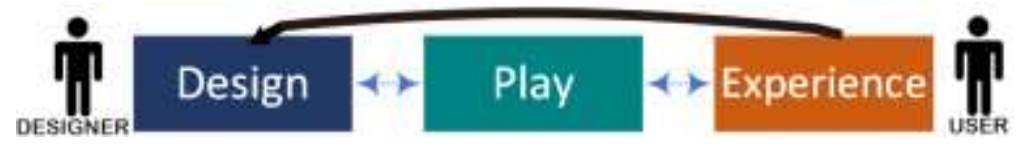

Gambar 1. Framework Design Play Experience (Brian M. Winn, 2016)

1) Design

Design adalah proses awal dalam perancangan untuk membuat game. Dalam proses ini, terdapat seorang perancang untuk mendesain game. Perancang hanya memiliki kendali langsung atas desain itu sendiri. Untuk mendesain permainan secara efektif, perancang terlebih dahulu harus datang dengan tujuan untuk mencari tahu pengalaman user (user experience). Tujuan ini digunakan untuk memandu desain dan untuk mengukur efektivitas dari desain yang akan diimplementasikan. Tahap design saling berhubungan dengan experience.

2) Play

Play merupakan tahap pembuatan game dan pengujian game yang telah dirancang. Play lebih berfokus pada penilaian dan bukan berdasarkan fakta. Contoh pengujian yang paling sering dilakukan oleh beberapa game developer adalah beta-testing. Pada beta-testing, game akan diujikan secara langsung pada beberapa pemain di luar pengembang, sehingga didapatkan experience dan feedback positif berkaitan dengan bugs yang perlu diperhatikan oleh pengembang pada pengujian sebelumnya. Hingga dapat disimpulkan bahwa tujuan utama dari play adalah untuk mengetahui apakah sebuah game dinilai cukup menyenangkan atau sebaliknya dengan tanpa bugs di dalam game.

\section{3) Experience}

Experience merupakan pengalaman yang dirasakan oleh user dengan kegiatan nyata saat bermain game dan kemudian memberikan feedback untuk game tersebut. Bermain game sangat dipengaruhi oleh tidak hanya design, tetapi juga pemain, termasuk latar belakang kognitif, sosial, budaya, dan experience bermain dari pemain. Oleh karena itu, experience satu pemain mungkin tidak seluruhnya sama dengan experience pemain lainnya. Target audiens untuk permainan harus sangat diperhitungkan selama proses design. Masing-masing lapisan framework DPE dan melalui alur kondisi yang sama, dimulai dari design, play, dan berakhir pada experience. Pada lapisan paling bawah adalah technology. Perancang tidak diharapkan untuk merancang sebuah technology, disadari (atau tidak) sebuah desain technology terbentuk dengan sendirinya [20]. 


\section{METODE PENELITIAN}

Penelitian ini terbagi menjadi enam tahap, yaitu perolehan data, perancangan game, implementasi perancangan, pengujian game dan analisis, tahap pengembangan dan pengujian akhir, dan publikasi ilmiah yang dapat dilihat pada Gambar 2.

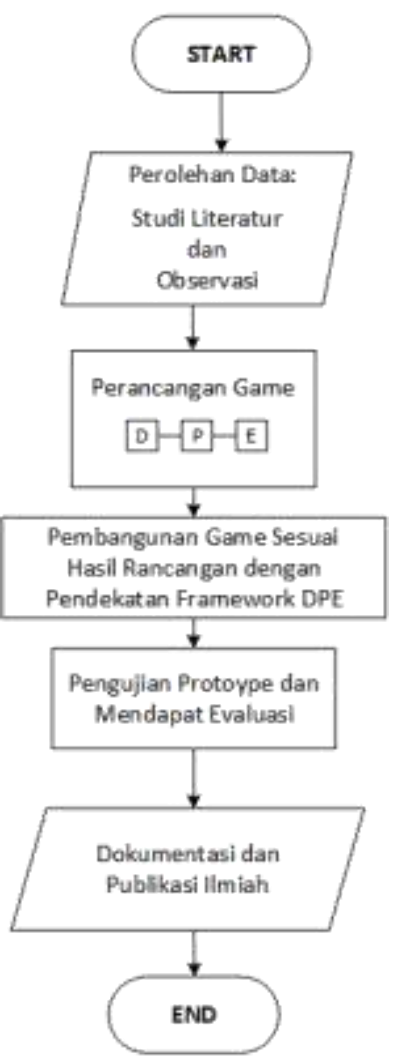

\section{Gambar 2. Diagram Alir Metode Penelitian}

\subsection{Perolehan Data}

Perolehan data dilakukan melalui cara observasi ke pemilik warung makan daerah khas Sumatera atau restoran makanan khas daerah Sumatera untuk pengumpulan data mengenai bahan yang diperlukan, cara pembuatan serta waktu yang dibutuhkan untuk membuat makanan tersebut. Studi literatur dilakukan untuk mendapat informasi tambahan dari tahap observasi. Informasi bisa didapatkan dari berbagai macam literatur.

\subsection{Perancangan Game}

Perancangan game menggunakan pendekatan DPE framework yang dibagi menjadi 3 bagian komponen yaitu Design, Play, dan Experience dan dijabarkan menjadi 5 layer yang masingmasing dari lapisan tersebut secara vertikal berinteraksi dan saling mempengaruhi dalam tahap perancangannya. Lapisan tersebut yaitu learning, storytelling, gameplay, user experience, dan technology. Masing-masing lapisan, melalui alur kondisi yang sama, dimulai dari design, play, dan berakhir pada experience. Pada lapisan paling bawah adalah teknologi. Perancang tidak diharapkan untuk merancang sebuah teknologi, disadari (atau tidak) sebuah desain itu sendiri berada pada teknologi (Ferdig, 2009). Gambar 3 merupakan penjabaran masing-masing layer yang terdapat pada DPE framework. 


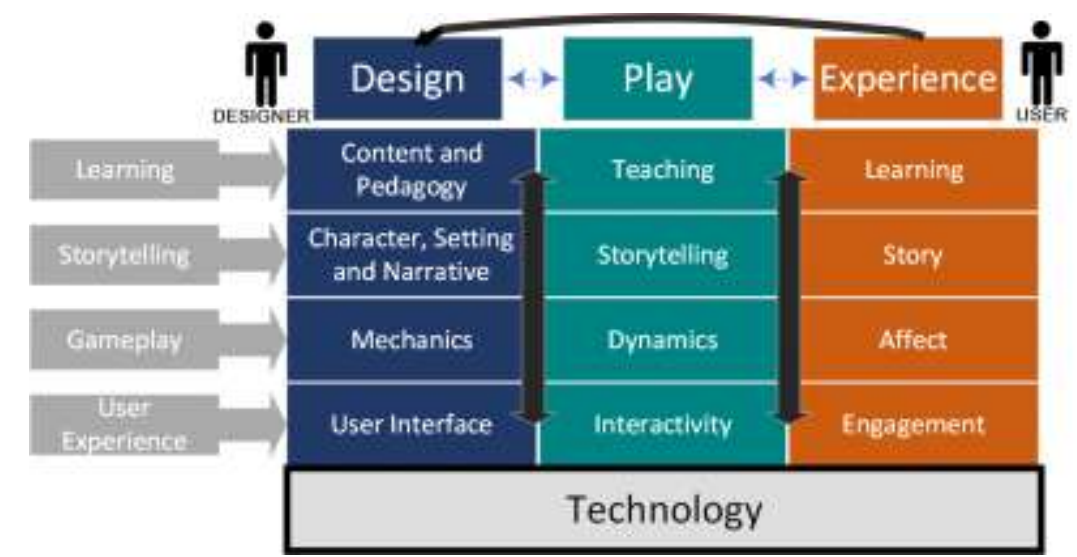

Gambar 3. Framework Design Play Experience (Brian M. Winn, 2016)

\subsection{Pembangunan Game}

Penerapan rancangan game, konsep, dan aset dalam bentuk perangkat lunak aplikasi video game dan menggunakan tools tambahan untuk memudahkan dalam penerapan rancangan.

\subsection{Pengujian Game}

Pengujian dilakukan untuk mengetahui bug atau kesalahan yang terdapat dalam game dan mendapatkan users goa/dalam mendapatkan pengalaman yang sama dengan kegiatan nyata.

\subsection{Dokumentasi Dan Publikasi Ilmiah}

Seluruh tahapan, proses penelitian dan hasil kesimpulan akan dimasukkan dalam bentuk laporan. Laporan penelitian akan disusun sesuai dengan ketentuan pedoman penulisan standar nasional.

\subsection{Learning Layer}

\section{IMPLEMENTASI DPE FRAMEWORK}

Learning layer digunakan dalam perancangan game simulasi memasak makanan daerah. Diasumsikan bahwa, apabila pemain dapat menyelesaikan game tersebut, cara memasaknya benar dan hasil masakannya itu lezat, maka pemain tersebut dapat melanjutkan ke tingkat selanjutnya. Sebaliknya, cara memasaknya tidak benar dan hasil masakannya itu tidak lezat, maka pemain tersebut harus menyelesaikan di tingkat tersebut. Tujuan dilakukannya learning layer ialah:

1) Meningkatkan kemampuan pemain untuk menentukan bahan masakan dan cara memasak yang tepat.

2) Mencapai user experience yang terdapat dalam game.

\subsection{Storytelling Layer}

Storytelling layer adalah layer untuk pembuatan alur cerita dalam game yang akan dibangun. Layer ini berfungsi menarik perhatian pemain untuk bermain game. Semakin menarik alur cerita yang dibuat, semakin seru pula game tersebut. Berdasarkan hasil wawancara dengan pemain, dilakukan survei berbentuk kuesioner untuk menentukan satu ide cerita yang merupakan saran dari pembuat game dan akan digunakan dalam game.

\subsection{Gameplay Layer}

Gameplay layer merupakan pola yang ditetapkan melalui peraturan dalam game, plot, dan hubungan antara pemain dengan game dimana pemain mengatasi tantangan dalam game. 
Gameplay pada sebuah game harus dibuat semenarik mungkin karena dapat mempengaruhi minat pemain.

\section{a. Challenges dan Levels}

Challenges digunakan untuk menantang pemain dalam melakukan permainan dan memberikan perasaan tertantang ketika berinteraksi dengan game agar game tidak terasa membosankan. Levels berfungsi untuk menunjukan status progress sudah sejauh mana karakter milik user menjelajah dan menemukan makanan baru di setiap daerahnya.

b. Interaksi pemain terhadap aplikasi

Interaksi terjadi saat pemain memulai memainkan game dan saat mempelajari bagaimana cara membuat makanan tersebut dengan arahan resep yang tersedia dalam game.

1) Karakter pada Game

Game yang akan dibangun terdapat Non-Playable Character (NPC) dimana NPC terdiri dari pemilik restoran, figuran dan karakter game sebagai koki sekaligus pembaca narasi cerita yang akan menjadi karakter milik pemain dan menemani pemain dalam game.

\subsubsection{Mekanika Game}

Mekanika merupakan hal yang dapat dilakukan pemain terhadap karakter. Pada game ini mekanika yang dibutuhkan adalah mekanika yang mencangkup aksi karakter untuk genre game simulasi seperti gerak dan berinteraksi dengan objek. Terdapat beberapa mekanika yang diterapkan pada game Cooking Brave, yaitu:

\section{1) Area Game}

Resolusi yang digunakan pada game adalah 1920 pixels x 1080 pixels, posisi kamera adalah Third Person Camera dan posisi kamera yang tetap di 2.5 dimensi (2.5D), kamera tidak dapat digerakan oleh pemain dan memiliki sudut Field of View sebesar 60 derajat dengan jarak pandang 500 meter. Gambar 4 adalah ukuran area permainan yang digunakan dalam game Cooking Brave.

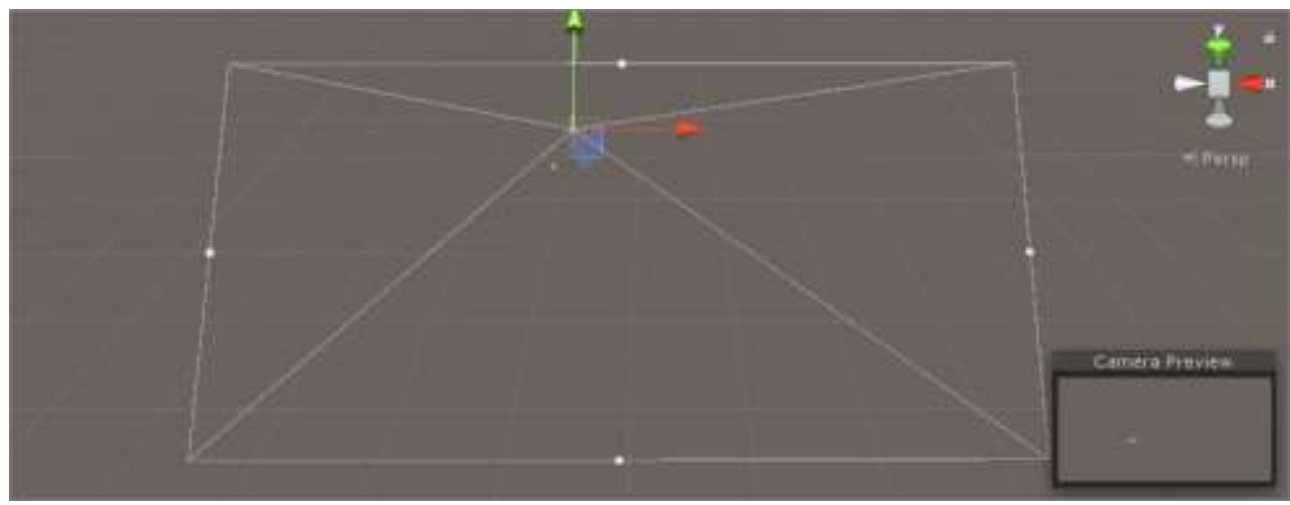

2) Kontrol Game

Gambar 4. Area Game Yang Digunakan Pada Game

Tombol arah atau D-Pad (Direction Pad) dan tombol aksi yang berada dalam permainan digunakan untuk melakukan pergerakan dasar dan aksi yang dapat dilakukan oleh karakter. Pergerakan dasar yang dapat dilakukan oleh karakter yaitu berjalan dan berlari. Sedangkan tombol aksi untuk melakukan suatu aksi yang dapat dilihat pada Gambar 5. 


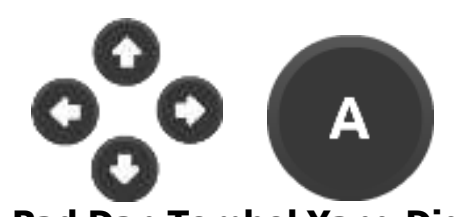

3) Tampilan Dasar

Gambar 5. Tombol D-Pad Dan Tombol Yang Digunakan Dalam Game

Tampilan-tampilan yang terdapat dalam game yaitu tampilan menu utama, storyboard, saat bermain dan reward.
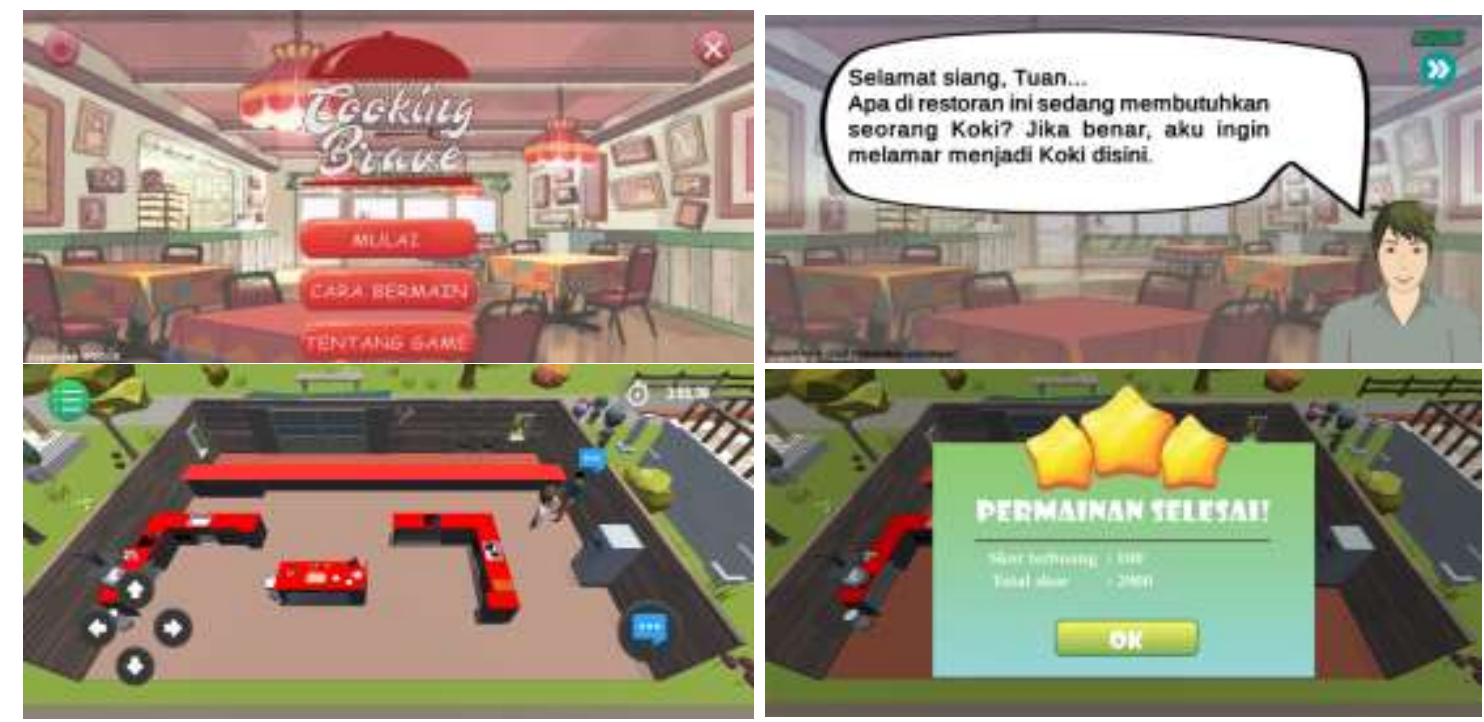

Gambar 6. Tampilan Dalam Game

4) Playable Character

Karakter yang dapat dimainkan oleh pemain. Karakter utama menampilkan animasi sebagai timbal balik ketika pemain melakukan hal tertentu pada mekanika di dalam game.

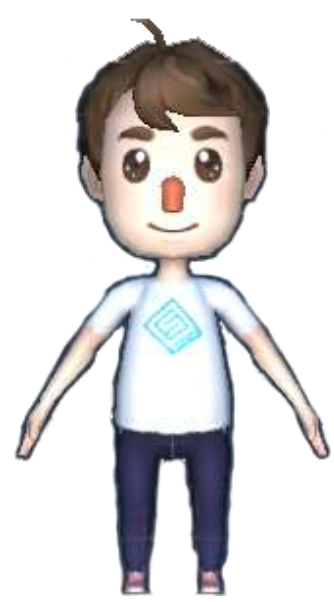

\section{Gambar 7. Playable Character}

5) Non-Playable Character

Karakter yang tidak dapat dimainkan oleh pemain. NPC dapat berperan sebagai karakter yang memberikan arahan kepada pemain, memberi tantangan kepada pemain dan sebagainya. 


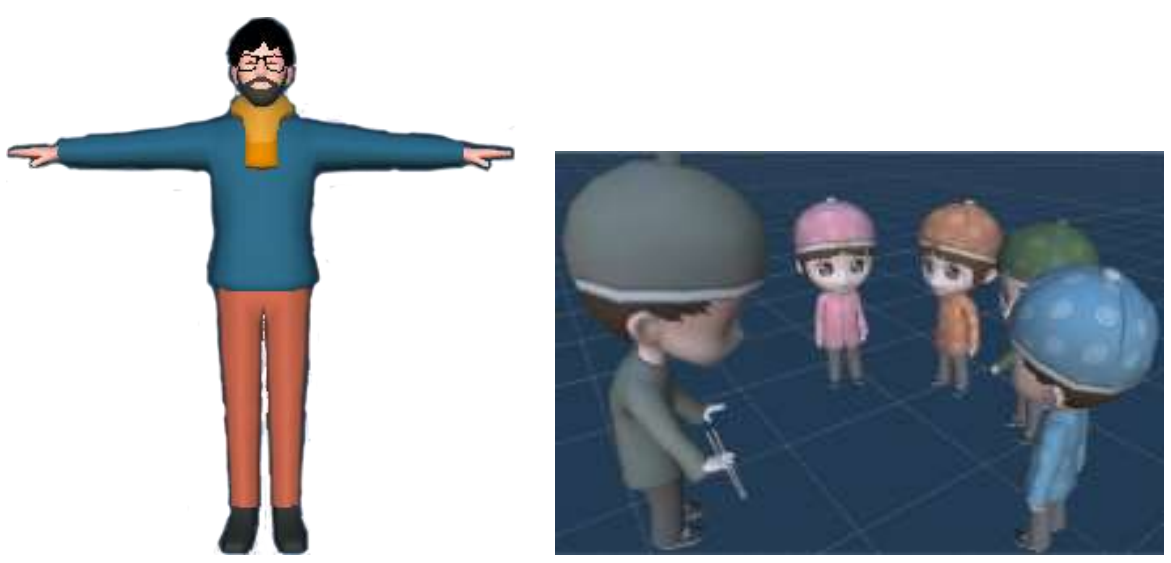

Gambar 8. Non-Playable Character

6) Objek Game

Objek yang digunakan dalam game adalah peralatan masak, bahan-bahan masak, kulkas, meja dan lain-lain.

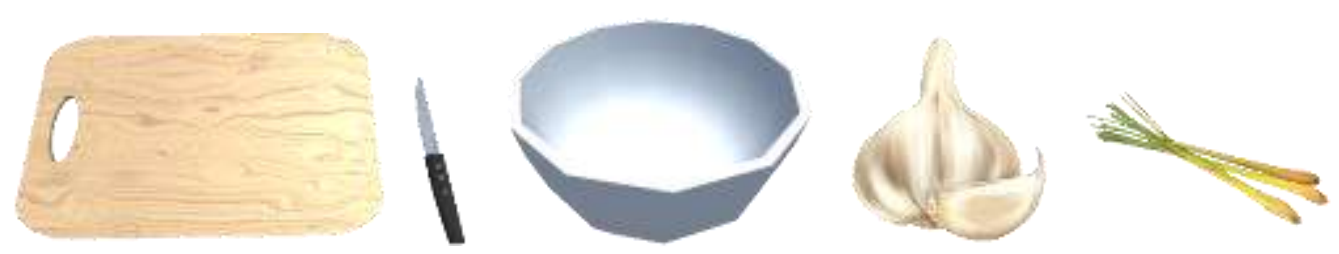

\section{Gambar 9. Objek Dalam Game}

\subsection{User Experience Layer}

User experience memberikan pengalaman kepada user dan mendapatkan respon emosional yang diinginkan pada saat user bermain game. User experience akan menghasilkan efek dari design pada user melalui sebuah bentuk dan tema graphics yang sesuai dengan game yang dibangun. Pengalaman yang akan dirasakan user berupa Sensation, Challenge dan Discovery.

1) Challenge

Pemain ditantang untuk menyelesaikan tantangan yang diberikan oleh Non-Playable Character.

\section{2) Sensation}

Respon pemain terhadap game. Pemain akan didesak karena terdapat batas waktu dalam memainkan game ini.

3) Discovery

Game pada penelitian ini terdapat beragam jenis makanan sehingga pemain dapat menelusuri keunikan dari makanan tersebut.

\subsection{TECHNOLOGY LAYER}

Technology layer merupakan hasil penggabungan rancangan dari keempat layer yaitu learning, storytelling, gameplay dan user experience yang kemudian menjadi sebuah teknologi (game).

\section{HASIL EVALUASI}

Pengujian dilakukan terhadap 30 orang. Responden merupakan masyarakat umum yang memainkan game Cooking Brave. Setelah game tersebut dimainkan, para responden mengisi 
kuesioner yang memuat pertanyaan mengenai tanggapan setelah memainkan game Cooking Brave.

Perhitungan hasil tanggapan kuesioner dihitung menggunakan skala Likert. Setiap tanggapan memiliki skor sebagai berikut:

1. $00,00-29,99=$ Sangat tidak sesuai

2. $30,00-49,99=$ Tidak sesuai

3. $50,00-69,99=$ Cukup sesuai

4. $70,00-89,99=$ Sesuai

5. $90,00-150=$ Sangat sesuai

Tabel 1. Hasil Perhitungan Tanggapan Kuesioner

\begin{tabular}{|c|c|c|c|c|}
\hline Aspek & Pertanyaan & $\begin{array}{c}\text { Indeks } \\
(\%)\end{array}$ & $\begin{array}{l}\text { Rata-Rata } \\
\text { Indeks (\%) }\end{array}$ & Kriteria \\
\hline \multirow{5}{*}{$\begin{array}{l}\text { Design } \\
\text { (User } \\
\text { Interface) }\end{array}$} & $\begin{array}{l}\text { Saya mudah mengendalikan } \\
\text { karakter dalam game }\end{array}$ & $70,6 \%$ & \multirow{5}{*}{$72,36 \%$} & \multirow{5}{*}{ Sesuai } \\
\hline & $\begin{array}{l}\text { Saya mengerti tugas yang saya } \\
\text { harus lakukan dalam game }\end{array}$ & $64,6 \%$ & & \\
\hline & $\begin{array}{l}\text { Saya mudah menggunakan fitur- } \\
\text { fitur yang terdapat dalam game }\end{array}$ & $74 \%$ & & \\
\hline & $\begin{array}{c}\text { Saya mengerti informasi dan fungsi } \\
\text { yang terdapat dalam game (buku } \\
\text { resep dan cara bermain) }\end{array}$ & $78 \%$ & & \\
\hline & $\begin{array}{l}\text { Saya mudah menekan icon gambar } \\
\text { bahan-bahan dan tombol yang ada } \\
\text { di dalam game }\end{array}$ & $74,6 \%$ & & \\
\hline \multirow[b]{2}{*}{$\begin{array}{l}\text { Experience - } \\
\text { Sensation }\end{array}$} & $\begin{array}{l}\text { Saya berkonsentrasi saat bermain } \\
\text { game }\end{array}$ & $67,3 \%$ & \multirow[b]{2}{*}{$72,65 \%$} & \multirow[b]{2}{*}{ Sesuai } \\
\hline & $\begin{array}{l}\text { Saya merasa senang dan tidak } \\
\text { terbebani saat bermain game }\end{array}$ & $79 \%$ & & \\
\hline \multirow[t]{2}{*}{$\begin{array}{l}\text { Experience - } \\
\text { Challenge }\end{array}$} & $\begin{array}{c}\text { Saya kesulitan mengingat bahan- } \\
\text { bahan yang diperlukan untuk } \\
\text { membuat salah satu jenis masakan } \\
\text { dengan batas waktu yang } \\
\text { ditentukan } \\
\end{array}$ & $55,3 \%$ & \multirow[t]{2}{*}{$65,3 \%$} & \multirow[t]{2}{*}{$\begin{array}{l}\text { Cukup } \\
\text { Sesuai }\end{array}$} \\
\hline & $\begin{array}{c}\text { Saya merasa kesulitan saat } \\
\text { melakukan aksi memasak dengan } \\
\text { batas waktu yang ditentukan }\end{array}$ & $75,3 \%$ & & \\
\hline $\begin{array}{l}\text { Experience - } \\
\text { Discovery }\end{array}$ & $\begin{array}{l}\text { Saya jadi mengetahui salah satu } \\
\text { makanan khas daerah yang } \\
\text { terdapat di provinsi Sumatera }\end{array}$ & $69,3 \%$ & $69,3 \%$ & $\begin{array}{l}\text { Cukup } \\
\text { Sesuai }\end{array}$ \\
\hline \multirow{2}{*}{$\begin{array}{l}\text { Edukasi dan } \\
\text { Simulasi }\end{array}$} & $\begin{array}{c}\text { Simulasi pembuatan makanan khas } \\
\text { daerah yang tersedia dalam game } \\
\text { tersampaikan dengan baik }\end{array}$ & $73,3 \%$ & \multirow[b]{2}{*}{$71,1 \%$} & \multirow[b]{2}{*}{ Sesuai } \\
\hline & $\begin{array}{c}\text { Dengan game simulasi ini saya } \\
\text { mengenal tentang cara membuat } \\
\text { makanan khas daerah tersebut dan } \\
\text { bahan-bahan yang diperlukan }\end{array}$ & $68 \%$ & & \\
\hline
\end{tabular}




\begin{tabular}{|c|c|c|c|c|}
\hline Aspek & Pertanyaan & $\begin{array}{c}\text { Indeks } \\
(\%)\end{array}$ & $\begin{array}{c}\text { Rata-Rata } \\
\text { Indeks (\%) }\end{array}$ & Kriteria \\
\hline & $\begin{array}{c}\text { Setelah belajar membuat masakan } \\
\text { daerah Sumatera dalam game } \\
\text { Cooking Brave, saya merasa dapat } \\
\text { mencoba untuk membuatnya } \\
\text { secara langsung }\end{array}$ & $72 \%$ & & \\
\hline
\end{tabular}

Pada Tabel 1 menunjukkan hasil perhitungan tanggapan pemain terhadap game. Berdasarkan hasil tersebut dapat disimpulkan bahwa game telah berhasil menerapkan aspek DPE framework, edukasi dan simulasi.

Tabel 2. Hasil Perhitungan Kuesioner Mengenai Materi

\begin{tabular}{|c|c|c|}
\hline Pertanyaan & Jawaban Benar (\%) & Jawaban Salah (\%) \\
\hline Pertanyaan 1 & $74,6 \%$ & $25,4 \%$ \\
\hline Pertanyaan 2 & $70,6 \%$ & $29,4 \%$ \\
\hline Pertanyaan 3 & $72 \%$ & $28 \%$ \\
\hline Pertanyaan 4 & $80 \%$ & $20 \%$ \\
\hline Rata-Rata & $\mathbf{7 4 , 3 \%}$ & $\mathbf{2 5 , 7 \%}$ \\
\hline
\end{tabular}

Berdasarkan pada Tabel 2, kuesioner berisi pertanyaan tentang pemahaman mengenai cara pembuatan makanan dan daya ingat pemain tentang bahan-bahan masakan. Responden melakukan pengisian ujian setelah bemain game tersebut pada kuesioner yang berkaitan dalam game Cooking Brave dengan nilai tertinggi yang tertuju pada pertanyaan poin empat dengan sebesar $80 \%$ dari 30 responden benar menjawab dan mendapat rata-rata skor $74,3 \%$.

\section{KESIMPULAN}

Penelitian ini telah menghasilkan sebuah desain game simulasi pembuatan masakan daerah yang diimplementasikan dengan menggunakan pendekatan DPE Framework.

Game telah diuji kepada 30 orang responden yang mencoba memainkan game. Sesuai dari hasil pehitungan kuesioner, para responden memiliki ketertarikan untuk bermain game yang memiliki genre simulasi dan edukasi sebesar $70,62 \%$ yang tertarik memasak sebesar $65,3 \%$ tetapi tidak mahir memasak sebesar $43 \%$. Game berhasil diterapkan menggunakan DPE Framework yang telah dirancang dimana aspek mengenai latar belakang pemain mendapat nilai sebesar 70,62\%, kemudian interaksi pemain dengan Design (user interface) game mendapat nilai rata-rata sebesar $72,36 \%$. Game berhasil mencapai tiga model Experience, yaitu Sensation berupa hasrat dalam memainkan game mendapat nilai sebesar $72,65 \%$, Challenge berupa respon emosional dari pemain mendapatkan nilai sebesar $65,3 \%$ dan Discovery berupa hal baru yang didapatkan pemain mendapatkan nilai sebesar 69,3\%. Game ini pula berhasil menyampaikan materi bagaimana cara membuat masakan daerah melalui media game dimana hasil tersebut didapatkan dari hasil pemahaman responden terhadap materi yang disampaikan dengan total rata-rata skor sebesar $71,1 \%$ dan soal pertanyaan pada ujian berhasil dijawab sebesar $74,3 \%$ oleh para responden. Dengan kata lain, game Cooking Brave unggul dalam penyajian emosional user experience berupa sensation yang dirasakan pemain saat bermain game tersebut dan memiliki rata-rata skor terbesar yaitu $72,65 \%$.

\section{UCAPAN TERIMAKASIH}

Terima kasih kepada para rekan dekat penulis yang sudah membantu dalam mencari inspirasi dan data-data yang diperlukan. Terima kasih juga kepada para responden atas ketersediaan waktunya sebagai sukarelawan uji coba game. 


\section{DAFTAR PUSTAKA}

[1] Rasyid Nur Harun, Ensiklopedi Makanan Tradisional Indonesia (Sumatera) - Google Play. 2004.

[2] Maisyaroh, "Edukasi Game Pengenalan Makanan Tradisional Indonesia Menggunakan Unity 2D," Univ. Muhamadiyah Surakarta, pp. 1-13, 2016.

[3] N. K. C. Wahyu Puspitawati, M. G. Sunarya, and I. K. R. Arthana, "Pengembangan Aplikasi Game 3D Tebak Rumah Dan Busana Adat Nusantara Berbasis Android," J. Pendidik. Teknol. dan Kejuru., vol. 12, no. 1, pp. 57-67, 2015.

[4] B. A. Binarsatya and N. A. Sani, "Rancang Bangun Aplikasi Game Avatar dengan Menerapkan Gamifikasi untuk Meningkatkan Minat Pengunjung Objek - Objek Bersejarah di Surabaya," J. Tek. ITS, vol. 7, no. 1, pp. 1-3, 2018.

[5] J. P. Astuti, "The Use Of Cooking Academy Game To Enrich Vocational Student's English Vocabularyt ( A Classroom Action Research at the Tenth Grade Students of SMK N 1 Mojosongo in the Academic Year of 2012 / 2013 ) FACULTY OF LANGUAGES AND ARTS," 2014.

[6] T. Haryadi and Aripin, "Melatih Kecerdasan Kognitif, Afektif, Dan Psikomotorik Anak Sekolah Dasar Melalui Perancangan Game Simulasi WARUNGKU," Jurnal Desain Komunikasi Visual dan Multimedia, vol. 1, no. 2, pp. 39-50, 2015.

[7] W. Huang and D. Soman, "Gamification Of Education," Univ. Toronto - Rotman Sch. Manag., pp. 1-29, 2013.

[8] G. B. Octaviani, D. Tri Ardianto, and Erandaru, "Perancangan Media Permainan Edukatif Pengenalan Jajanan Tradisional untuk Anak Usia 9-12 Tahun di Surabaya," Peranc. Media Permainan Edukatif Pengenalan Jajanan Tradis. untuk Anak Usia 9-12 Tahun di Surabaya, pp. 1-11, 2011.

[9] F. Yasin and A. Irsyadi, "Pengenalan Makanan Khas Asli Indonesia Melalui Game Edukasi," Fak. Komun. dan Inform. Univ. Muhammadiyah Surakarta, pp. 27-40, 2016.

[10] P. Thavikulwat, "The architecture of computerized business gaming simulations," Simul. Gaming, vol. 35, no. 2, pp. 242-269, 2004.

[11] R. Mellecker, E. J. Lyons, and T. Baranowski, "Disentangling Fun and Enjoyment in Exergames Using an Expanded Design, Play, Experience Framework: A Narrative Review," Games Health J., vol. 2, no. 3, pp. 142-149, 2013.

[12] M. R. Z. Riawan, W. S. Wardhono, and T. Afirianto, "Penerapan DPE Framework dalam Perancangan Serious Game bagi Pengidap Kebutaan Nada," Pengembangan Teknologi Informatika dan Ilmu Komputer, vol. 1, no. 10, pp. 1008-1017, 2017.

[13] R. Ibrahim and A. Jaafar, "Educational games (EG) design framework: Combination of game design, pedagogy and content modeling," Proc. 2009 Int. Conf. Electr. Eng. Informatics, ICEEI 2009, vol. 1, no. August, pp. 293-298, 2009.

[14] N. I. Widiastuti and I. Setiawan, "Membangun Game Edukasi Sejarah Walisongo," Jurnal Ilmu Komputer dan Informatika, vol. 1, no. 2, pp. 41-48, 2012.

[15] D. F. P. Ghea, "Pengembangan Game Edukasi Pengenalan Nama Hewan Dalam Bahasa Inggris Sebagai Media Pembelajaran Siswa Sekolah Dasar Berbasis Macromedia Flash", 2012.

[16] B. W. Sari, E. Utami, H. Al, B. W. Sari, E. Utami, and H. Al Fatta, "Pembelajaran Tenses Bahasa Inggris Berbasis Web," Jurnal IImu SISFOTENIKA, vol. 5, no. 2, pp. 155-166, 2015.

[17] N. Dony, "Aplikasi Game Geografi Berbasis Multimedia Interaktif (Studi Kasus Kelas IX SMPN 1 RAO)," vol. 6, no. 2, pp. 106-118, 2013. 
[18] W. Walk, D. Görlich, and M. Barrett, "Design, dynamics, experience (DDE): An advancement of the MDA framework for game design," Game Dyn. Best Pract. Proced. Dyn. Game Content Gener., pp. 27-45, 2017.

[19] R. E. Ferdig, K. Klinger, K. M. Roth, M. Boyer, B. M. Winn, and A. Appicello, "The Design, Play, and Experience Framework", vol. 3.

[20] R. E. Ferdig, K. Klinger, K. M. Roth, M. Boyer, and A. Appicello, "Handbook of Research on Effective Electronic Gaming in Education," vol. 3, 2009. 